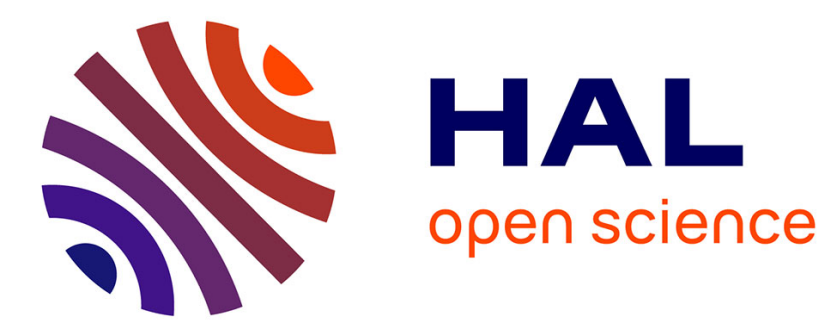

\title{
Determinants of blood eosinophilia in moderate and severe asthmatic patients during childhood: evidence from the SAMP cohort
}

Jocelyne Just, Sarah Saf, Tamazoust Guiddir, Nathalie Cottel, Flore Amat, Nathalie Lambert, Philippe Saint-Pierre, Mélisande Bourgoin-Heck

\section{To cite this version:}

Jocelyne Just, Sarah Saf, Tamazoust Guiddir, Nathalie Cottel, Flore Amat, et al.. Determinants of blood eosinophilia in moderate and severe asthmatic patients during childhood: evidence from the SAMP cohort. Pediatric Allergy and Immunology, 2021, 10.1111/pai.13507 . hal-03190188

\section{HAL Id: hal-03190188 \\ https://hal.sorbonne-universite.fr/hal-03190188}

Submitted on 6 Apr 2021

HAL is a multi-disciplinary open access archive for the deposit and dissemination of scientific research documents, whether they are published or not. The documents may come from teaching and research institutions in France or abroad, or from public or private research centers.
L'archive ouverte pluridisciplinaire HAL, est destinée au dépôt et à la diffusion de documents scientifiques de niveau recherche, publiés ou non, émanant des établissements d'enseignement et de recherche français ou étrangers, des laboratoires publics ou privés. 
1 Determinants of blood eosinophilia in moderate and severe asthmatic patients during

2 childhood: evidence from the SAMP cohort

3 Short Title: Eosinophilia significance in SAMP cohort

4 Jocelyne JUST MD, $\mathrm{PhD}^{1,2,3}$, Sarah $\mathrm{SAF} \mathrm{MD}^{1,3}$, Tamazoust GUIDDIR $\mathrm{MD}^{1,3}$, Nathalie

5 COTTEL MD ${ }^{1,3}$, Flore AMAT MD ${ }^{1,2,3}$, Nathalie LAMBERT MD ${ }^{1,3}$, Philippe SAINT-PIERRE

$6 \mathrm{PhD}^{5}$, Mélisande BOURGOIN-HECK MD ${ }^{1,3}$.

\section{$7 \quad$ Affiliations}

$8{ }^{1}$ Department of Allergology, Hôpital d'Enfants Armand Trousseau, APHP, 26 avenue du Dr 9 Netter, 75012 Paris, France

$102^{2}$ Sorbonne Universités, Paris 06, Paris, France

$11{ }^{3}$ Equipe EPAR, Institut Pierre Louis d'Epidémiologie et de Santé Publique, UMR_S1136, 12 INSERM

$13{ }^{4}$ Laboratory of Biochemistry and Molecular Biology- Laboratoire de Biochimie et Biologie 14 Moléculaire, Hôpital d'Enfants Armand Trousseau, Assistance Publique-Hôpitaux de Paris, 15 Paris, France

$16{ }^{5}$ Institute of mathematics, Toulouse III Paul-Sabatier University, Toulouse, France

17 Corresponding author: Jocelyne JUST, MD, $\mathrm{PhD}$

Department of Allergology — Centre de l'Asthme et des Allergies

19 Hôpital d'Enfants Armand Trousseau 
2026 avenue du Dr Arnold Netter, 75012 Paris, France

21 jocelyne.just@aphp.fr

22 Total word count: 2827 ; Abstract: 216; References: 32; Tables: 5; Figures: 3 
23 Conflict of interest: Jocelyne JUST has received personal fees from Novartis, Thermofischer and Astra Zeneca and grant from Novartis. Sarah SAF, Tamazoust GUIDDIR, Nathalie COTTEL, Flore AMAT, Nathalie LAMBERT, Philippe SAINT-PIERRE and Mélisande BOURGOIN-HECK have no conflict of interest

Funding sources: Grant has been provided from ASTRA ZENECA for this publication

\section{Abstract}

Background: Asthma is a heterogeneous disease in which the interaction of genetic and environmental factors plays a major role. The significance of blood eosinophil is unclear. The aim of the study was to determine the significance of blood eosinophil count in moderate to severe asthmatic children of preschool and school age.

Methods: This was a prospective cross-sectional study performed from 2011 to 2015 including children from the Severe Asthma Molecular Phenotype (SAMP) cohort at Trousseau Hospital (Paris, France). We included children with severe and moderate asthma, or severe and moderate recurrent wheeze, aged from 1 to 15 years at the time of exploration.

Results: We analyzed data from 402 children: 248 of preschool age and 154 of school age. Blood eosinophil count third quartile thresholds were 322 and 600 cells $/ \mu \mathrm{L}$ for the preschooland school-age groups, respectively. In multivariate analysis, a blood eosinophil count over this threshold was associated with elevated total $\operatorname{IgE}(\mathrm{OR}=5.33 ; P<0.01)$, multiple hospitalizations for asthma attacks $(\mathrm{OR}=4.96 ; P=0.03)$, and a maternal history of asthma $(\mathrm{OR}=4.91 ; P=0.01)$ in preschool children; and with staphylococcal toxin-specific $\operatorname{IgE}(\mathrm{OR}=2.75 ; P=0.03)$ in children of school age. Random forest analysis reinforced these results. 
45 Conclusion: High blood eosinophil count is linked to both atopic features and control of asthma 46 with different parameters associated with these features depending on age.

47

48 Keys words: asthma phenotype; children; eosinophil; severe asthma; staphylococcal toxin 49 sensitization 


\section{Abbreviations:}

51 EVW: Episodic viral wheeze

52 ICS: Inhaled corticosteroids

53 MTW: Multiple trigger wheeze

54 SAMP: Severe Asthma Molecular Phenotype

55 SPT: Skin prick tests 
56

57

\section{Introduction}

Asthma is a heterogeneous disease in which genetic and environmental factors play a major role(1). It has been known since the end of the 1950s that the sputum eosinophil count is a predictor of the response to treatment with corticosteroids(2). In adults, the presence of eosinophils in asthma inflammation is an important factor in the disease pathophysiology and blood eosinophil count can be used as a non-invasive biomarker to identify patients with an improved response to some treatments $(3,4)$. Several interesting studies have been carried out to determine the role of eosinophils in the management of asthma, but controversy persists. Some studies suggest that eosinophilic driven biomarkers (such as exhaled nitric oxide, sputum eosinophil count and blood eosinophil count) are associated with more severe asthma or with a poorer disease outcome in adults(5-7). One recent publication analyzing the response to mepolizumab in adults with severe eosinophilic asthma, reported that the blood eosinophil count was a better predictor of response than sputum eosinophil count(8). Furthermore, determining the sputum eosinophil count is a particularly complex and costly technique which is not available in all health centers. On the other hand, blood eosinophil count can be routinely measured in all clinical settings. Consequently, peripheral eosinophil assessment is a more practical option for determining the asthma phenotype in both adults and children. However, discrepancies about the significance of blood eosinophil count have been reported: some studies have observed that adult patients with high eosinophil count have more severe asthma $(5,6)$, while others have described the opposite with fewer severe exacerbations reported(9), or even no correlation at all(10). Finally, the range of blood eosinophil count would appear to differ between children and adult asthmatic populations(11). The aim of this study was to determine the significance of high blood eosinophil count in preschool- and school-age children. 


\section{Methods}

80

81

\section{Design and setting}

This was a prospective cross-sectional study performed from 2011 to 2015 from the SAMP cohort at Trousseau Hospital, Paris (France). All the children had been referred to the center by a secondary or primary physician due to persistence of recurrent wheeze despite long-term treatment. The Institutional Review Board of Saint Antoine Hospital, Paris, endorsed the protocol as an observational study. Written informed consent was obtained from the parents of the children included.

The children included in the present study met the following inclusion criteria: children with severe and moderate asthma or severe and moderate recurrent wheeze aged from 1 to 15 years at the time of exploration (12)

Health outcomes were collected in a computerized database using standardized questionnaires. Gender and age at inclusion were collected. The severity of asthma or recurrent wheeze of the entire population was assessed after at least 6 months of follow-up prior to inclusion in the study by an experienced pulmonologist paediatrician after repeated individual or group health education measures had been undertaken to improve adherence to a continuous anti-asthmatic treatment, and after advice by an environmental specialist to reduce exposure to indoor biological pollutants. Severe asthma was defined as controlled asthma with high doses of inhaled corticosteroids (ICS) ( $\geq 500 \mu \mathrm{g}$ /day fluticasone propionate) and two other controller medications in school-age children; and as controlled symptoms with high doses of ICS ( $>200$ $\mu \mathrm{g} /$ day fluticasone propionate) and leukotriene receptor antagonist in preschool-age patient. 
100 The daily dosage of ICS was recorded. Children were classified as having either episodic viral

101

102

103

104

105

106

107

108

109

110 wheeze (EVW) (wheezing only during colds and remaining asymptomatic between episodes) or multiple trigger wheeze (MTW) (wheezing during colds but symptomatic between episodes with wheezing activated by dust, grass, pets, tobacco smoke, exercise or cold air). Totally controlled asthma was defined as the absence of nocturnal or daily symptoms, exacerbation, short-acting $\beta 2$-agonist use or activity limitation due to asthma, according to Global Initiative for Asthma(1). Partially control or uncontrolled asthma were defined as the presence of one or two of these parameters and uncontrolled asthma as the presence of three or four. The number of hospitalizations for an asthma attack in the year prior to inclusion was recorded. Both maternal and paternal asthma histories were collected. Allergic rhinitis and active atopic dermatitis were assessed by questions from the International Study of Asthma and Allergies in Childhood (ISAAC)(13), and IgE-mediated food allergy was defined by clinically relevant symptoms within 6 hours following food allergen consumption associated with an allergic sensitization to the same allergen. Total IgE (measured by ImmunoCAP, Thermofischer, Uppsala, Sweden) were collected. The following thresholds were used to define increased levels: elevated total $\operatorname{IgE}$ above or equal to the third quartile distribution of each studied population (total population, preschool-age group (children $<6$ years) and school-age group (children $\geq 6$ years). Allergic sensitization was defined by positive skin prick tests (SPT) (mean weal diameter $\geq 3 \mathrm{~mm}$; Stallergenes, Antony, France $)$ and/or positive specific IgE levels $(\geq 0.35$ kIU/L, measured by ImmunoCAP, Thermofischer, Uppsala, Sweden) for cow's milk, egg, current inhaled allergens and staphylococcal toxins. Perennial sensitization was defined as house dust mite and/or cat or dog dander sensitization without associated seasonal allergen sensitization. Seasonal sensitization was defined as grass and/or birch pollens sensitization, 
123 with no associated perennial sensitization. Perennial and seasonal co-sensitization was defined

124 as the sensitization of at least one perennial and one seasonal allergen as described above.

125 Sensitization to food allergen was defined as cow's milk and/or egg sensitization or peanut 126 sensitization.

127 Data about habitation density (categorized as $\leq 9 \mathrm{~m}^{2}$ per household member (high) or $>9 \mathrm{~m}^{2}$ per 128 household member (low)); tobacco smoke exposure (based on smokers in the home, including 129 mother, father, or other adult household members); and potential biologic allergens sources as 130 molds at home (visible or moldy smell) were collected by means of a questionnaire validated 131 in the PARIS neonatal cohort(14).

\section{Blood eosinophilic count}

133 Blood eosinophil count was measured by an automated Sysmex analyzer (Villepinte, France) 134 outside systemic corticoid treatment and asthma exacerbations. Moreover, eosinophil count 135 stability was assessed by at least two measures within the last 6 months of follow-up. High and 136 low blood eosinophil counts were defined as above or equal to the third quartile distribution 137 and under the third quartile distribution of blood eosinophil count, respectively, in each of the 138 three groups (total population, preschool-age and school age groups).

\section{Statistical analysis}

140 The chi-square test and Fisher's exact test were used to compare the distribution of each variable

141 (clinical and environmental) between the high and low blood eosinophil count groups. A 142 logistic regression analysis was used to investigate the relationships between the binary 143 outcome of interest (high blood eosinophil count) and multiple risk factors. Univariate and 
144 multivariate models were constructed to better understand the presence of high blood eosinophil

145 count. Risk factors associated with high blood eosinophil count in the univariate analysis $146(P<0.2)$ and parameters known to be associated with high blood eosinophil count in the 147 literature (i.e., multiple hospitalizations for asthma attacks and uncontrolled asthma) were 148 included in the multivariate analysis. The multivariate models were selected using the backward 149 stepwise procedure based on Akaike Information Criteria.

150 A tree-based analysis was then performed to propose non-linear approaches to understand the 151 presence of high blood eosinophil count. In a first step, classification and regression trees were 152 considered to obtain a non-linear classifier able to distinguish between high and low blood 153 eosinophil counts, the variables at the top of the tree being more predictive of high blood 154 eosinophil count. In a second step, a random forest analysis was performed to provide another 155 selection of important variables to predict high blood eosinophil count. This ensemble method 156 uses a number of classification trees to improve the classification compared to a single tree. In 157 addition to good predictive performance, random forests estimate the relevance (discriminating 158 power) of each variable using importance measures (permutation-based mean decrease in 159 accuracy). All analyses were two-sided, and a $P$-value $\leq 0.05$ was considered statistically 160 significant. Statistical analysis was performed with R version 3.5.0. The R package 'glm', 161 'Rpart' and 'randomForest' were used to perform the analyses. 
162

\section{Results}

163

Four hundred and two children were included of whom 248 were of preschool age and 154 of

164 school age. The population's characteristics are summarized in Table I. Elevated total IgE

165 (above or equal to the third quartile distribution) was 344,105 , and $920 \mathrm{kIU} / \mathrm{L}$ in the total 166

population, the preschool-age group and the school-age group, respectively.

\section{High and low blood eosinophil count groups}

Blood eosinophil count third quartile thresholds were 440,322 and 600 cells per $\mu \mathrm{L}$ in the total population, the preschool-age group and the school-age group, respectively (Table II).

More features of allergy were apparent in the high blood eosinophil count group (Table II). This group had more allergic comorbidities, especially more allergic rhinitis $(P<.001)$, more inhaled and food allergen sensitization, especially peanut sensitization $(P<.001)$ and cow's milk and/or egg sensitization $(P<.001)$, and more elevated total $\operatorname{IgE}(P<.001)$ (Figure 1). This group also had more children with MTW $(P \leq .001)$. Blood eosinophil count was not significantly associated to asthma control and to ICS doses, in the total population, the preschool-age group and the school-age group ( $P$-values: $0.547,0.385$ and 0.814 for asthma control; and 0.949 , 0.554 and 0.596 for ICS doses, respectively), as presented in Figure 2. Similarly, Total IgE levels were not significantly associated to asthma control and to ICS doses, in the total population, the preschool-age group and the school-age group ( $P$-values : $0.52,0.072$ and 0.769 for asthma control; and $0.679,0.075$ and 0.763 for ICS doses, respectively), as presented in Figure 3.

\section{High blood eosinophil count risk factors}


183 In multivariate analysis, a model was developed using an automatic stepwise procedure taking

184 parameters with $P<0.2$ in univariate logistic regression analysis (Table II) and parameters 185 known to be associated with high blood eosinophil count in the literature (i.e., multiple 186 hospitalizations for asthma attack and uncontrolled asthma). After adjustment, this analysis led 187 to a model indicating that the following parameters increased the risk of high blood eosinophil 188 count in the entire population: older age $(\mathrm{OR}=1.01 ; P<.01)$, at least two hospitalizations for 189 asthma attacks $(\mathrm{OR}=5.40 ; P=0.01)$, allergic rhinitis $(0 \mathrm{R}=3.44 ; P<.01)$ and sensitization to 190 peanut $(\mathrm{OR}=2.67 ; P=0.04)$ (Table III).

191 Similarly, in the preschool-age population, elevated total $\operatorname{IgE}(\mathrm{OR}=5.33 ; P<.01)$, at least two 192 hospitalizations for asthma attacks in the previous year ( $\mathrm{OR}=4.96 ; P=0.03)$, and a maternal 193 history of asthma $(\mathrm{OR}=4.91 ; P=0.01)$ were found to increase the risk of high blood eosinophil 194 count (Table IV). The importance measure (permutation measure) obtained from the random 195 forest analysis can be interpreted as a measure of discriminating power. These measures 196 reinforced the previous results: the most important variables to explain high blood eosinophil 197 count were elevated total $\operatorname{IgE}$ and at least two hospitalizations for asthma attacks. Maternal 198 asthma history and cow's milk and/or egg sensitization were other determinants of high blood 199 eosinophil count at preschool age.

200 In the school-age population, staphylococcal toxin-specific $\operatorname{IgE}$ sensitization $(\mathrm{OR}=2.75$; $201 P=0.03$ ) was found to increase the risk of high blood eosinophil count after adjustment (Table 202 V). The importance measures obtained from the random forest analysis also reinforced the 203 previous results of determinants of high blood eosinophil count (sensitization to staphylococcal toxins) but also identified MTW and cow's milk and/or egg sensitization. 


\section{Discussion}

206 The principal result of our study was that high blood eosinophil count was positively correlated 207 with elevated total IgE and at least two hospitalizations for asthma attacks in the previous year, 208 but also with a maternal history of asthma at preschool age, and to staphylococcal toxin-specific 209 IgE sensitization at school age.

\section{Increase in blood eosinophil count during childhood}

211 It is well known that blood eosinophil count has different range levels during childhood in the

212 general population: in the peripheral blood it varies by age group with higher upper threshold 213 limits seen in infants and toddlers compared to adolescents and adults(15). We have previously 214 described that eosinophil count is more frequently associated with severe asthma in school-age 215 children than in preschool-age children(12).

\section{High blood eosinophil count determinants and atopic features}

217 The correlation between eosinophilia and total IgE level, especially in preschool cohorts, has 218 often been associated with poor asthma prognosis during childhood(16). More recently, a 219 prospective controlled trial showed that significantly higher levels of total serum IgE levels, 220 blood eosinophil count and fractional exhaled nitric oxide were correlated with an atopic asthma 221 group compared to a non-atopic asthma group(17). In the same manner, Park et al(18), in a 222 cohort of preschool children with a follow-up of 2 years, showed that serum eosinophil 223 percentage and total IgE were associated with an increased risk of allergic sensitization and 224 allergic symptoms. 
225 Both maternal and paternal histories of asthma are associated with an increased risk of asthma 226 in the offspring with a stronger association for maternal asthma history(19). In the MAS cohort(20) a positive allergic family history was a strong predictor of asthma from childhood up to adulthood.

We found that staphylococcal toxin-specific IgE sensitization was the major determinant of high blood eosinophil count in children of school age. Staphylococcal colonization of the skin

231 is commonly observed in subjects with atopic dermatitis and correlates with disease severity.

232 In atopic dermatitis, results suggest that exotoxins incite a local super-antigen response, with 233 clonal T-cell activation and massive cytokine release, which has been correlated with disease 234 severity. Staphylococcus aureus colonization was more commonly observed in subjects with 235 atopic dermatitis who had peripheral eosinophilia, elevated serum IgE levels, and/or a history 236 of or active allergic rhinitis(21). Staphylococcal toxin-specific IgE has also been found in the 237 serum of patients with chronic sinusitis with nasal polyps(22). Our results are in accordance 238 with a phenotype of severe asthma at school age with high blood eosinophil count, elevated 239 total IgE level and multiple sensitizations(23). As in atopic dermatitis, staphylococcal toxin240 specific IgE significantly alter epithelial repair(24) and could initiate clonal T-cell activation 241 and multiple sensitizations associated with eosinophilic inflammation and asthma severity.

242 We found that food allergy was associated with high blood eosinophil count in multivariate 243 analysis in the whole population (peanut sensitization OR 2.67, $P=0.04$ ) and cow's milk and/or 244 egg sensitization (in random forest analysis at preschool and at school age) but with fewer repetitive links than the other atopic determinants in the various statistical analyses.

246 Finally, the two atopic determinants of high blood eosinophil count are probably associated 
247 with genetic traits of atopy in preschool children (maternal asthma history and elevated total $248 \mathrm{IgE}$ ) and/or innate traits of atopy in children of school age (staphylococcal toxin-specific IgE) 249 in relation with the long-term temporal trajectory of allergic diseases.

250

251

252

253

254

255

256

257 finding(27). In a retrospective cohort study of 2,701 patients(28), those with uncontrolled

258 asthma and high blood eosinophil count were four times more likely to be hospitalized and the associated costs were more than four times greater than for patients with controlled asthma without high blood eosinophil count.

261 In our study, a high blood eosinophil count at school age tended to be associated, though without 262 reaching statistical significance, with $\mathrm{MTW}(\mathrm{OR}=7.41, P=0.07)$. Moreover, MTW was the first 263 determinant factor for high blood eosinophil count in random forest analysis at school age. The 264 distinction between EVW and MTW is used to guide the management of preschool wheeze(29). 265 In the literature, MTW is more often associated with asthma severity than EVW, especially in 266 allergic children, and with persistence of asthma throughout childhood: severe disease was 267 more frequent in children with MTW (31.8\%) than in those with EVW (5.1\%) in a cross268 sectional survey of children of 7-12 years of age in Aberdeen city primary schools(30). In the 
269

270

271

272

273

274

275

276

277

278

279

280

281

283

284

prospectively followed Trousseau Asthma Program cohort, we showed that remission was more frequently observed in children with EVW and that fewer remissions were observed in atopic MTW.

Finally, in the literature, an eosinophilic asthma phenotype(31) has been associated with disease severity(32) but consequently to uncontrolled asthma in 544 subjects: the eosinophilic phenotype, according to blood eosinophil count, was associated with uncontrolled asthma $(\mathrm{OR}=1.56 ; 95 \% \mathrm{CI}[1.06-2.28])$.

The strength of the present study is that it was performed in a large and well-defined population of children with severe asthma or severe recurrent wheeze. On the other hand, a main limitation lies in the fact that all the patients were recruited from one center. Nevertheless, while twothirds of the asthmatic children were from Paris and the surrounding area $(>10$ million inhabitants), the remaining one-third live in regions throughout France, which limits this potential bias. Finally, another limitation is that the study was cross-sectional.

In conclusion, high blood eosinophil count in children with moderate and severe asthma is associated with different features depending on age. This finding suggests that blood eosinophil count could be a useful pharmacodynamic biomarker for a specific pathological pathway to better define the target of biologic drugs.

Acknowledgments: The authors thank Rémi Couderc, Yannick Chantran, Marie-Ange Selva, Pascal Poncet and Hélène Sénéchal for their help in the assessment of biological parameters in this study. 


\section{Key message}

292 In this study, we highlight that elevated blood eosinophil count in moderate to severe asthmatic 293 children has different significance according to age; mainly elevated IgE, multiple 294 hospitalizations and maternal asthma history for preschool-age children and staphylococcal 295 toxin-specific sensitization for children of school age. These results could help understand the pathophysiology of asthma inflammation and lead to better management by targeted therapy. 
297

298

299

300

301

302

303 for the study of bronchial inflammation in the control of patients with asthma. Int Arch Allergy

304 Immunol 2015: 166:1-12.

305

4. Albers FC, Müllerová H, Gunsoy NB et al. Biologic treatment eligibility for real-world

306 patients with severe asthma: The IDEAL study. J Asthma Off J Assoc Care Asthma 2018:

$307 \quad 55: 152-160$.

308 5. Silkoff PE, Strambu I, Laviolette M et al. Asthma characteristics and biomarkers from

309 the Airways Disease Endotyping for Personalized Therapeutics (ADEPT) longitudinal profiling

310 study. Respir Res 2015: 16. doi:10.1186/s12931-015-0299-y

311 6. Amelink M, de Groot JC, de Nijs SB et al. Severe adult-onset asthma: A distinct 312 phenotype. J Allergy Clin Immunol 2013: 132:336-341.

313 7. Inoue H, Ito I, Niimi A et al. CT-assessed large airway involvement and lung function 314 decline in eosinophilic asthma: The association between induced sputum eosinophil differential 315 counts and airway remodeling. J Asthma Off J Assoc Care Asthma 2016: 53:914-921.

316 8. Katz LE, Gleich GJ, Hartley BF et al. Blood eosinophil count is a useful biomarker to 18 
317 identify patients with severe eosinophilic asthma. Ann Am Thorac Soc 2014: 11:531-536.

318 9. Pola-Bibian B, Dominguez-Ortega J, Vilà-Nadal G et al. Asthma exacerbations in a 319 tertiary hospital: clinical features, triggers, and risk factors for hospitalization. $J$ Investig 320 Allergol Clin Immunol 2016: :0.

321 10. Price DB, Rigazio A, Campbell JD et al. Blood eosinophil count and prospective annual 322 asthma disease burden: a UK cohort study. Lancet Respir Med 2015: 3:849-858.

323 11. Humbert M, Taillé C, Mala L et al. Omalizumab effectiveness in patients with severe 324 allergic asthma according to blood eosinophil count: the STELLAIR study. Eur Respir J 2018:

325 51. doi:10.1183/13993003.02523-2017

326 12. Guiddir T, Saint-Pierre P, Purenne-Denis E et al. Neutrophilic Steroid-Refractory 327 Recurrent Wheeze and Eosinophilic Steroid-Refractory Asthma in Children. J Allergy Clin 328 Immunol Pract 2017: 5:1351-1361.e2.

329 13. Asher MI, Keil U, Anderson HR et al. International Study of Asthma and Allergies in 330 Childhood (ISAAC): rationale and methods. Eur Respir J 1995: 8:483-491.

331 14. Clarisse B, Nikasinovic L, Poinsard R et al. The Paris prospective birth cohort study: 332 which design and who participates? Eur J Epidemiol 2007: 22:203-210.

333 15. Taylor MR, Holland CV, Spencer R et al. Haematological reference ranges for 334 schoolchildren. Clin Lab Haematol 1997: 19:1-15.

335 16. Castro-Rodriguez JA. The Asthma Predictive Index: a very useful tool for predicting 336 asthma in young children. J Allergy Clin Immunol 2010: 126:212-216. 
337 17. Shrestha SK, Drews A, Sharma L et al. Relationship between total serum

338 immunoglobulin E levels, fractional exhaled breath nitric oxide levels and absolute blood 339 eosinophil counts in atopic and non-atopic asthma: a controlled comparative study. $J$ Breath $340 \quad$ Res 2018: 12:026009.

341 18. Park SC, Kim JH, Lee K-H et al. Association of serum eosinophilia and total 342 immunoglobulin E concentration with the risk of allergic symptoms and allergic sensitization, 343 respectively: A 2-year follow-up study. Int J Pediatr Otorhinolaryngol 2016: 86:167-171.

344 19. Lim RH, Kobzik L, Dahl M. Risk for asthma in offspring of asthmatic mothers versus 345 fathers: a meta-analysis. PloS One 2010: 5:e10134.

346 20. Lau S, Matricardi PM, Wahn U et al. Allergy and atopy from infancy to adulthood: 347 Messages from the German birth cohort MAS. Ann Allergy Asthma Immunol Off Publ Am Coll 348 Allergy Asthma Immunol 2019: 122:25-32.

21. Warner JA, McGirt LY, Beck LA. Biomarkers of Th2 polarity are predictive of 350 staphylococcal colonization in subjects with atopic dermatitis. Br J Dermatol 2009: 160:183185.

22. Conley DB, Tripathi A, Ditto AM et al. Chronic sinusitis with nasal polyps: staphylococcal exotoxin immunoglobulin E and cellular inflammation. Am J Rhinol 2004: 18:273-278.

23. Just J, Gouvis-Echraghi R, Rouve $\mathrm{S}$ et al. Two novel, severe asthma phenotypes identified during childhood using a clustering approach. Eur Respir J 2012: 40:55-60.

357 24. Valera FCP, Ruffin M, Adam D et al. Staphylococcus aureus impairs sinonasal 20 
358 epithelial repair: Effects in patients with chronic rhinosinusitis with nasal polyps and control 359 subjects. J Allergy Clin Immunol 2019: 143:591-603.e3.

360 25. Simpson A, Tan VYF, Winn J et al. Beyond atopy: multiple patterns of sensitization in 361 relation to asthma in a birth cohort study. Am J Respir Crit Care Med 2010: 181:1200-1206.

362 26. Herr M, Just J, Nikasinovic L et al. Risk factors and characteristics of respiratory and 363 allergic phenotypes in early childhood. J Allergy Clin Immunol 2012: 130:389-396.e4.

364 27. Bafadhel M, Greening NJ, Harvey-Dunstan TC et al. Blood Eosinophils and Outcomes 365 in Severe Hospitalized Exacerbations of COPD. Chest 2016: 150:320-328.

366 28. Casciano J, Krishnan J, Dotiwala Z et al. Clinical and Economic Burden of Elevated 367 Blood Eosinophils in Patients With and Without Uncontrolled Asthma. J Manag Care Spec 368 Pharm 2017: 23:85-91.

369 29. Spycher BD, Cochrane C, Granell R et al. Temporal stability of multitrigger and 370 episodic viral wheeze in early childhood. Eur Respir J 2017: 50. doi:10.1183/13993003.000143712017

372 30. Tagiyeva N, McNeill G, Russell G et al. Two main subtypes of wheezing illness? 373 Evidence from the 2004 Aberdeen schools asthma survey. Pediatr Allergy Immunol Off Publ 374 Eur Soc Pediatr Allergy Immunol 2008: 19:7-12.

375 31. Lima-Matos A, Ponte EV, de Jesus JPV et al. Eosinophilic asthma, according to a blood 376 eosinophil criterion, is associated with disease severity and lack of control among 377 underprivileged urban Brazilians. Respir Med 2018: 145:95-100. 
378 32. Bousquet J, Chanez P, Lacoste JY et al. Eosinophilic inflammation in asthma. $N$ Engl J 379 Med 1990: 323:1033-1039. 
$\tilde{\omega}$

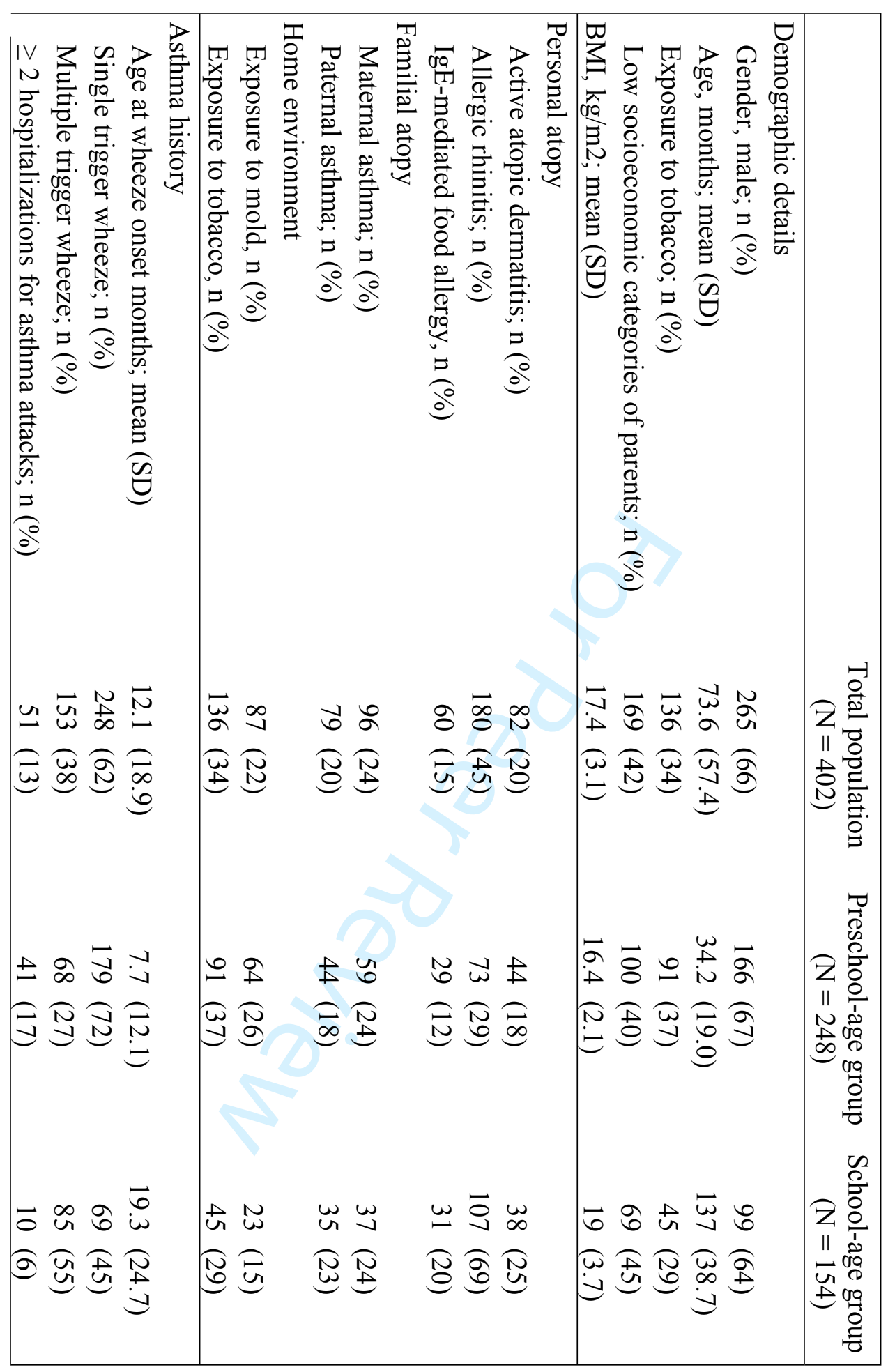




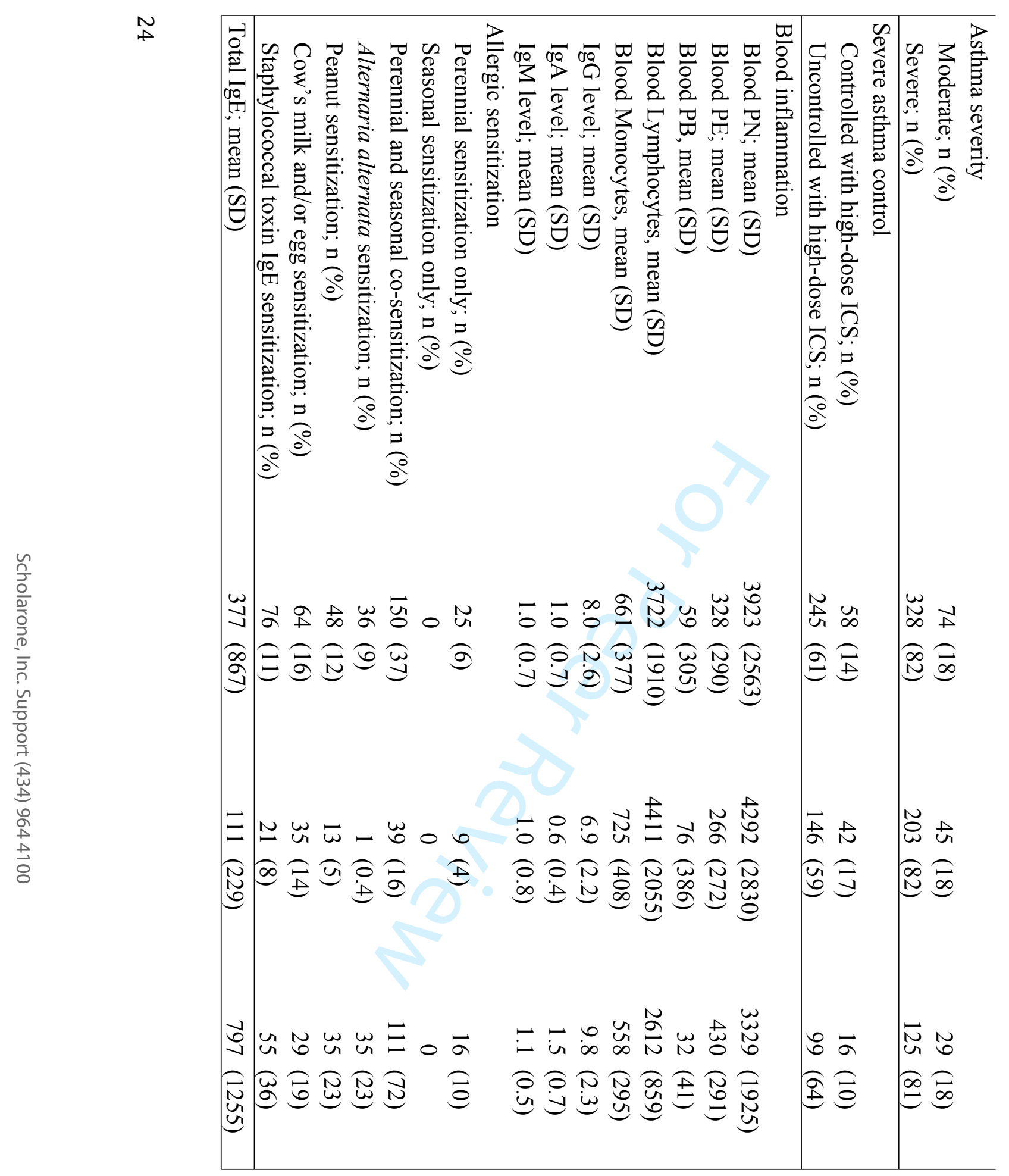


ก

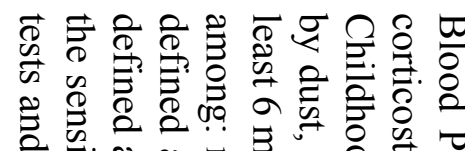

政:

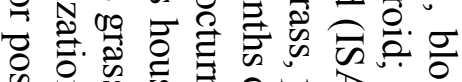

는 .

क्ष

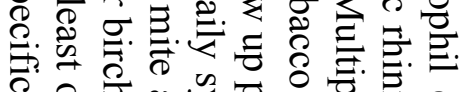

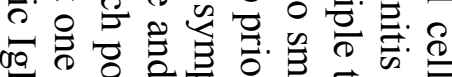

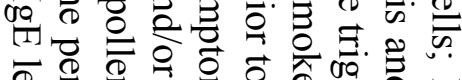

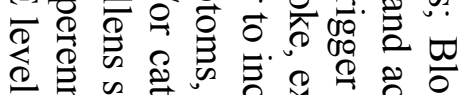
क人

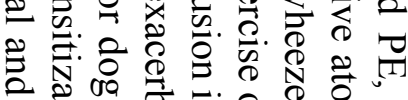

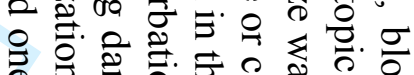
年

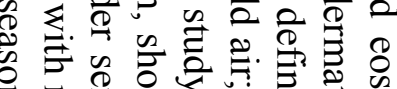

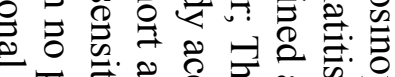

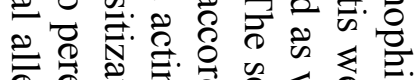
영

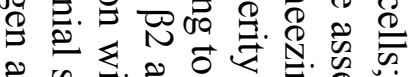

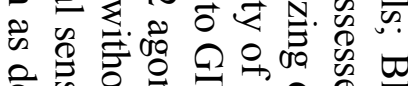

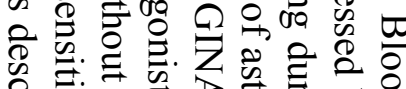
政

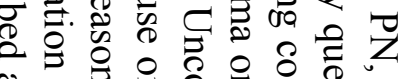
空

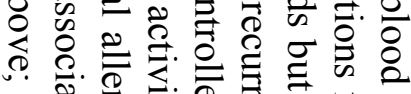

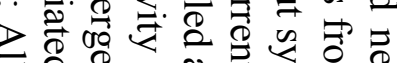

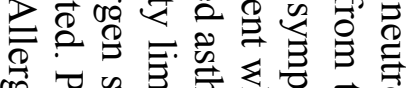

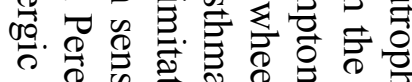

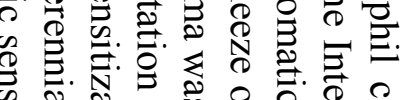
할.

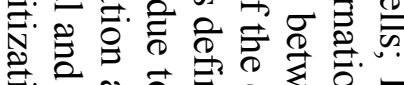
.

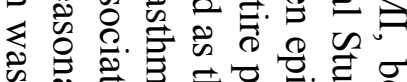

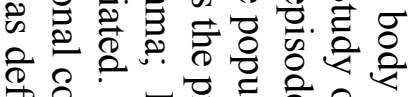

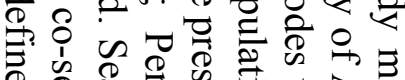

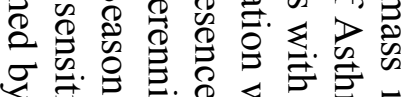

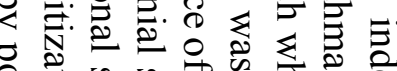

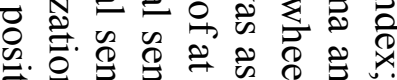
들. 6

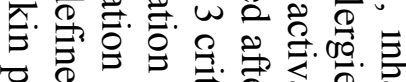

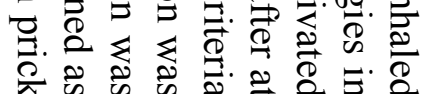




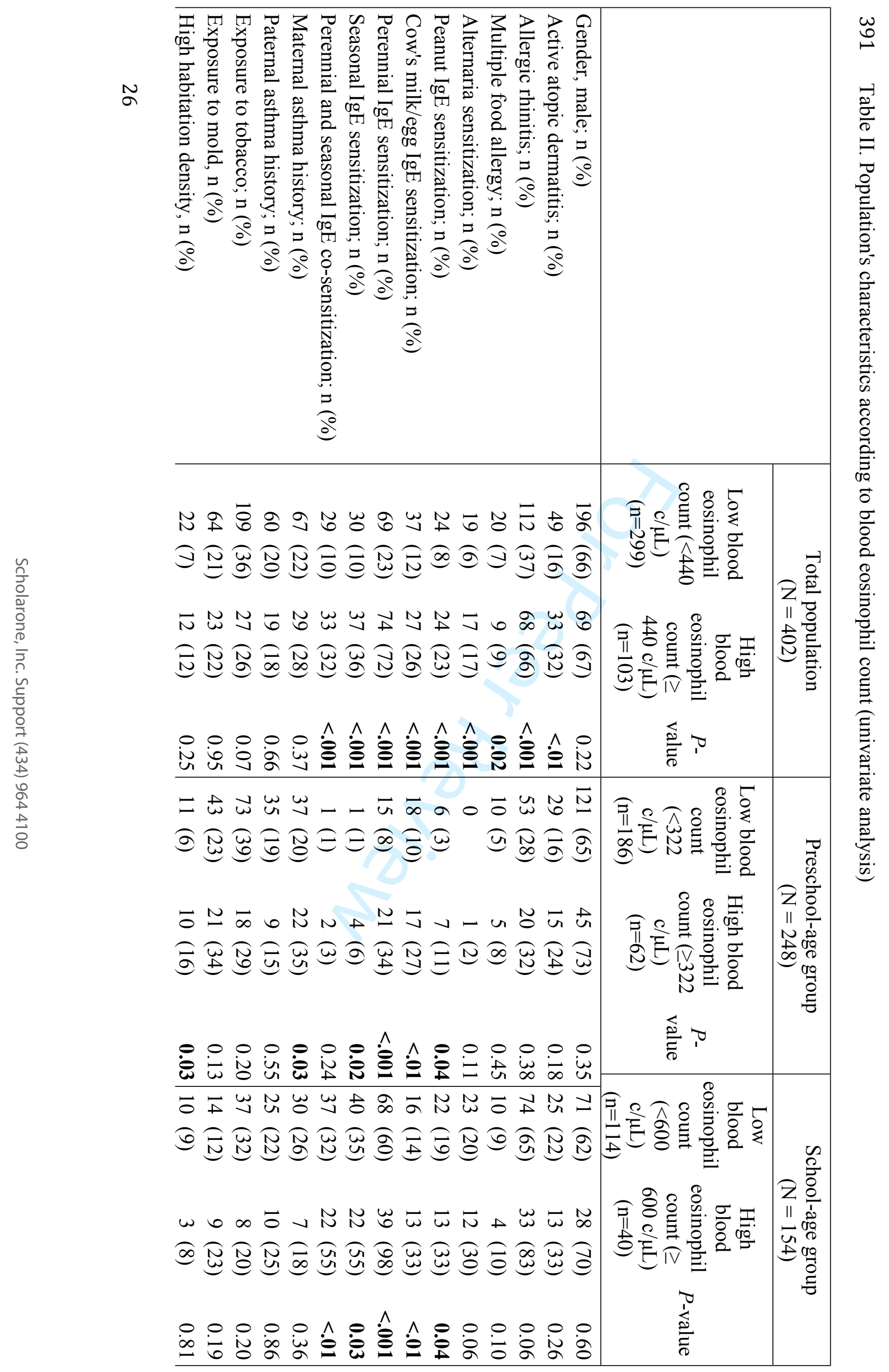




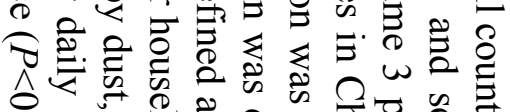

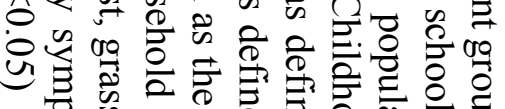

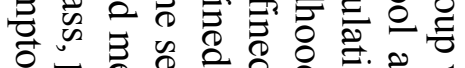

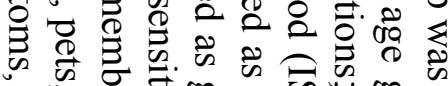

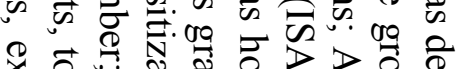

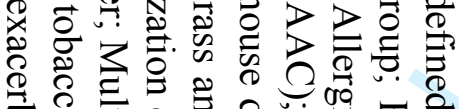

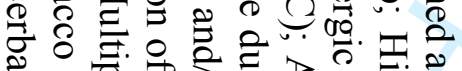

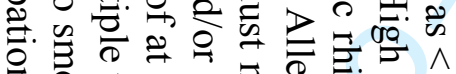

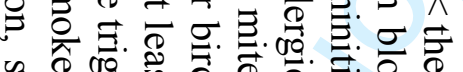

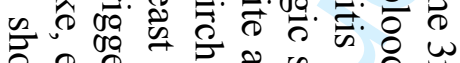

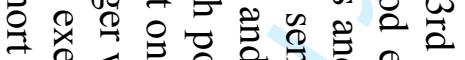
है

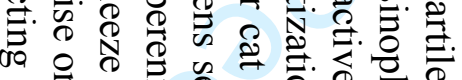

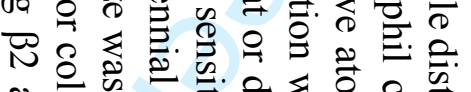
ก के के

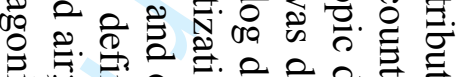
品灾 苛

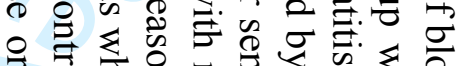

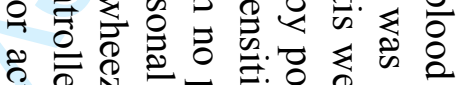

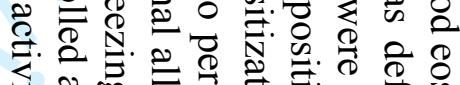

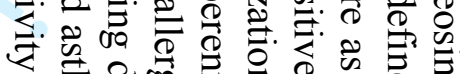

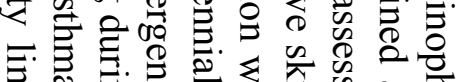

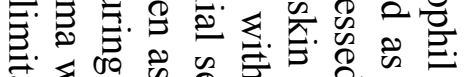

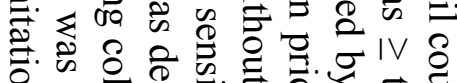

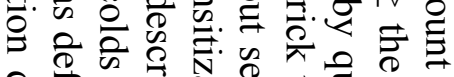

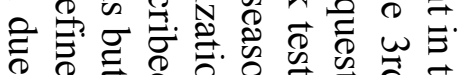

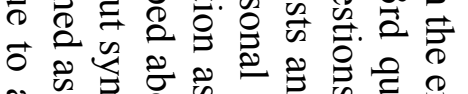

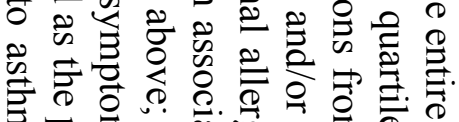

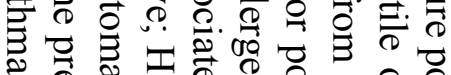
?

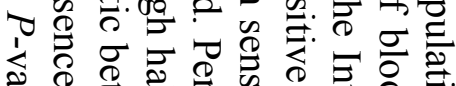

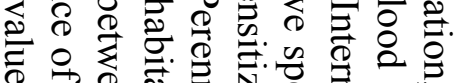

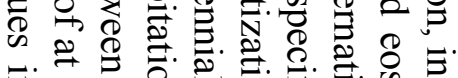

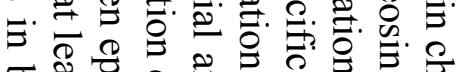

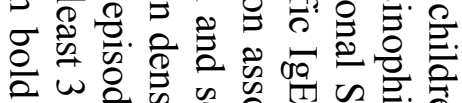

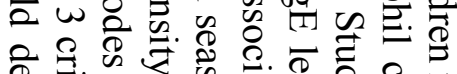

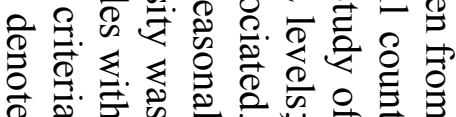

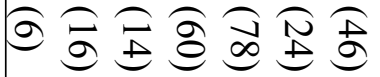

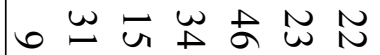

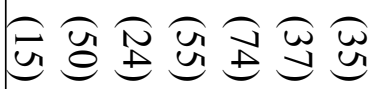

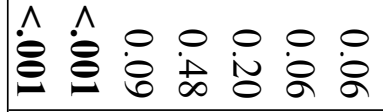
w

岕

$\vec{\infty} \omega \tilde{U} \sim N N$

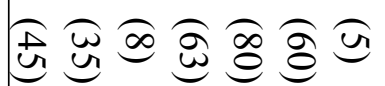

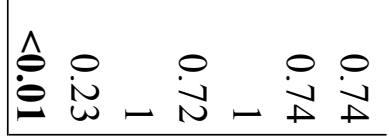




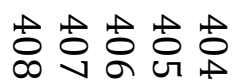

$\stackrel{0}{\omega}$

$\stackrel{\infty}{\infty}$
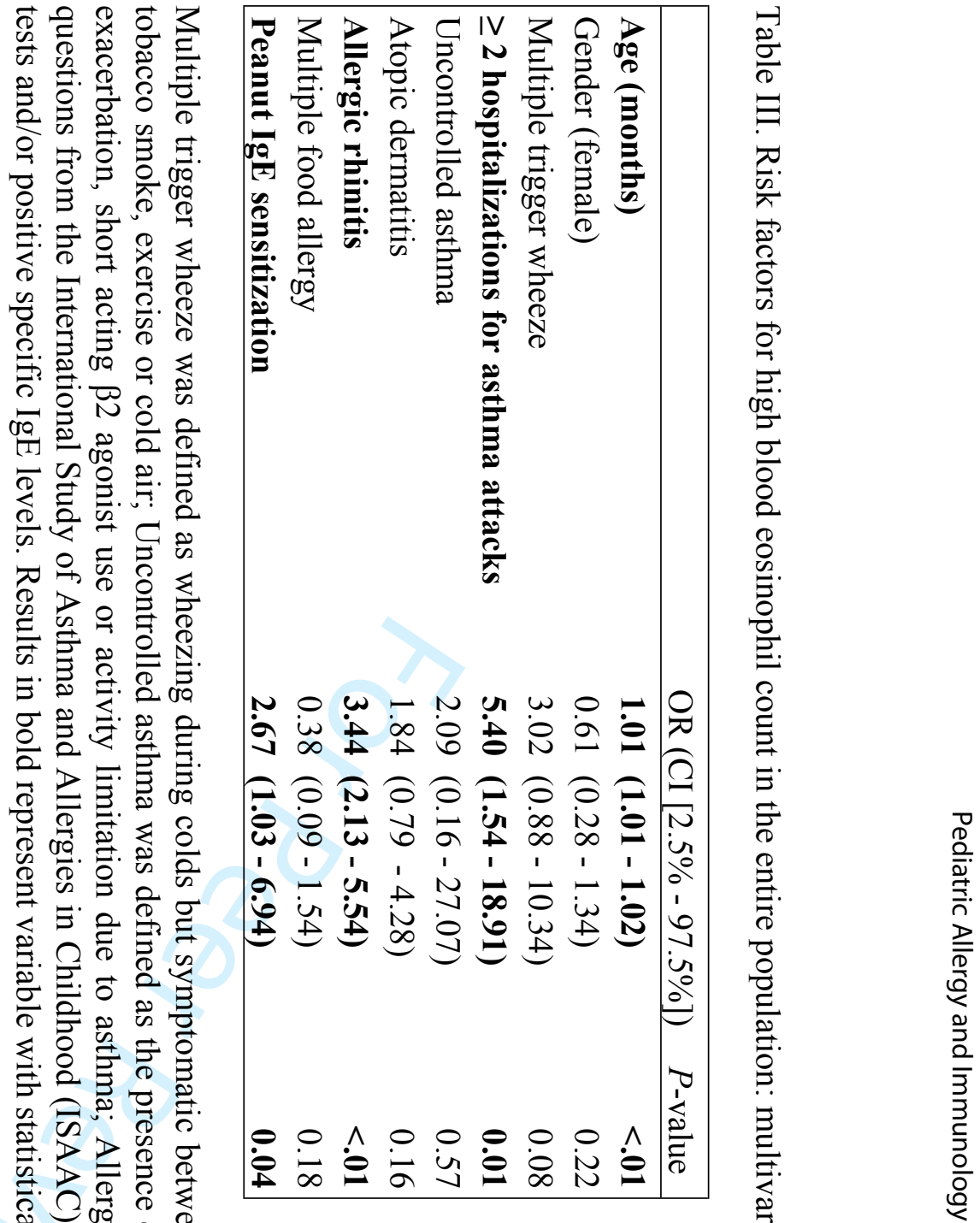

u $\rightarrow \circ \stackrel{8}{9}$

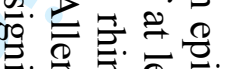

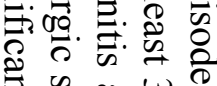

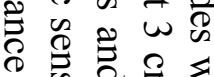

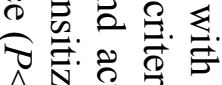

응 ڤ્己.

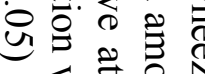

苍莡.

용ㅇํㅇ 융

芯怘莒

。

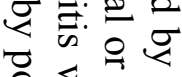

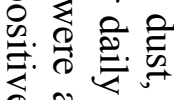

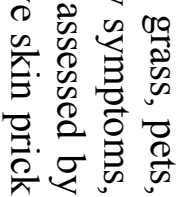

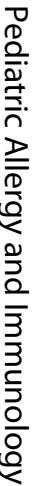


莫苔芯苦

$\stackrel{p}{\omega}$

$\ddot{o}$

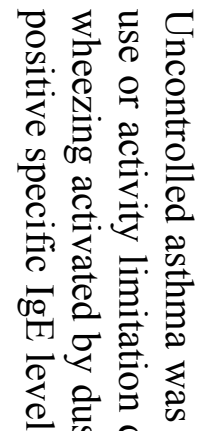

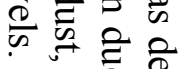

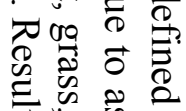

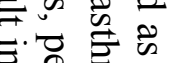
ठ 유융

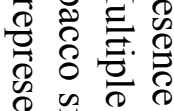

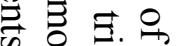
$<$ त्रि

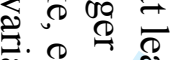

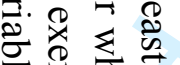

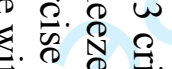
妾 0 ○

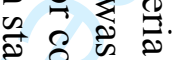
‥

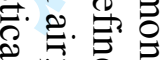
o 00

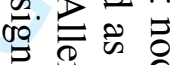
实祭. 声

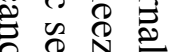
尺 จิ ڤ્. ○节. 䓍

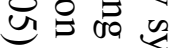
$\sum \delta \Xi$ की के 品寻 त) is

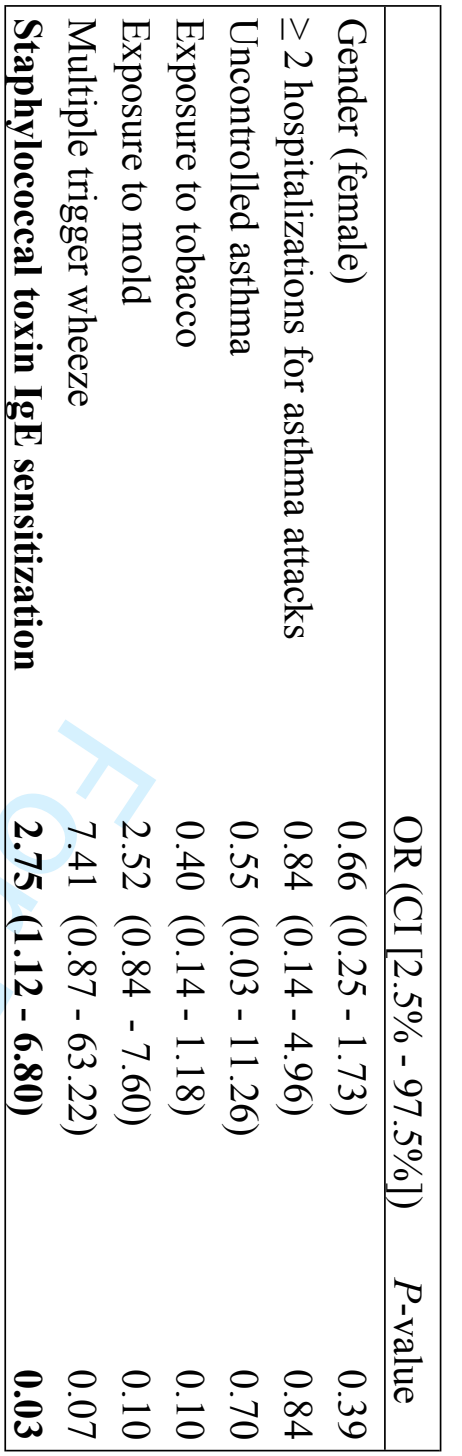

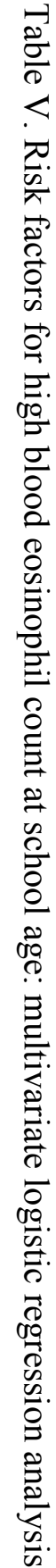

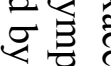

- $\overrightarrow{0}$

员. 节. ¿. ㄱ.

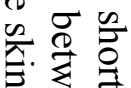
들. § त串 旅

थ \&

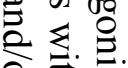

을 占. 


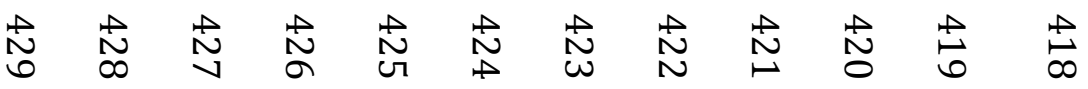

$\stackrel{\omega}{\sim}$

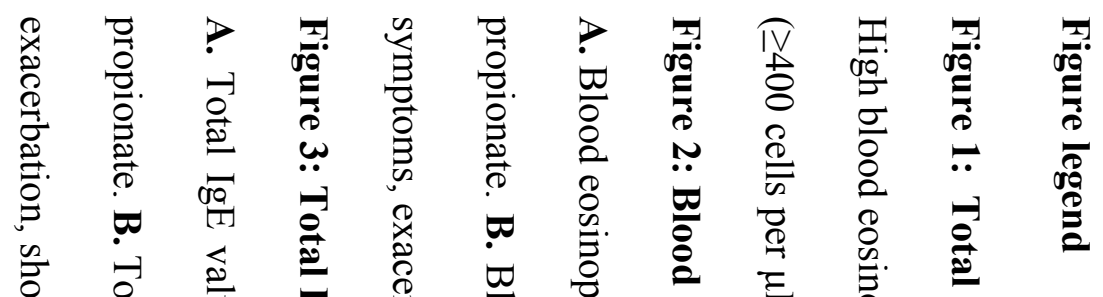

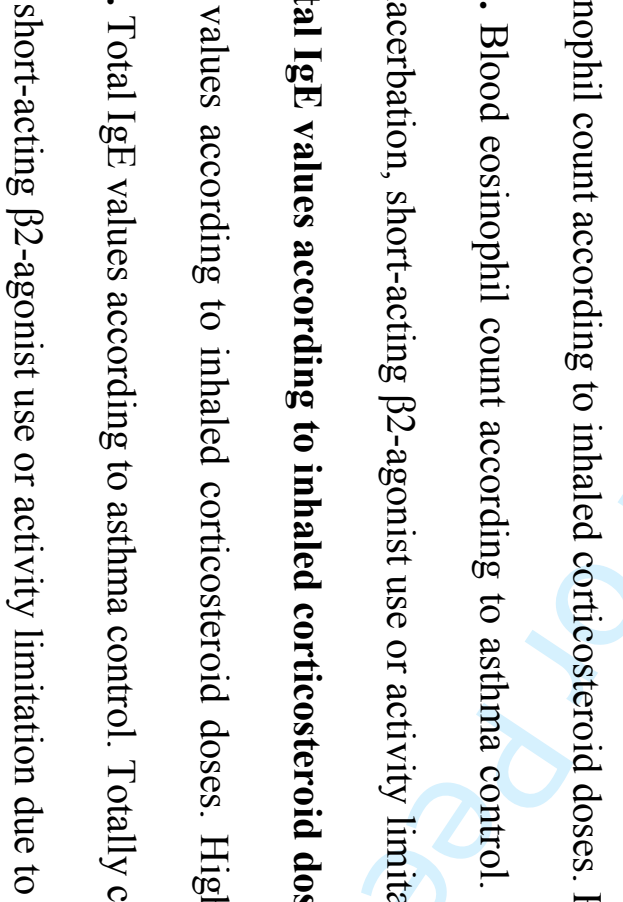

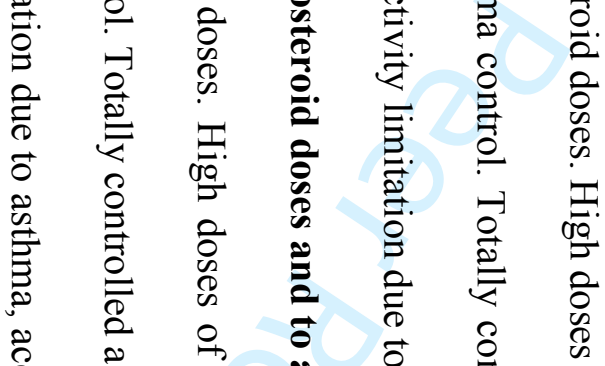

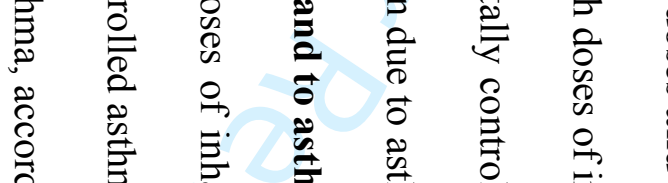

言

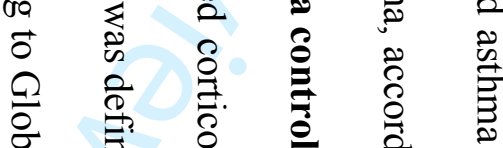

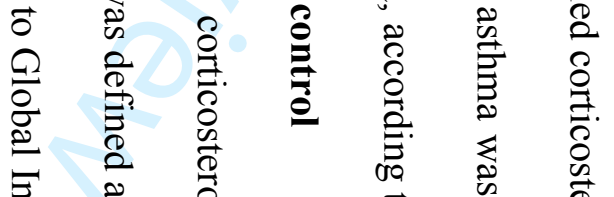

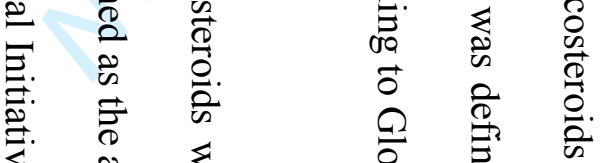

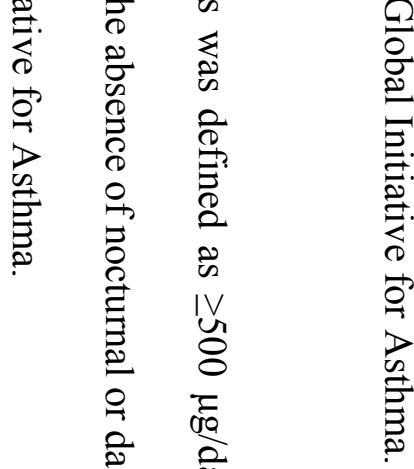

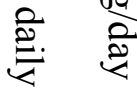

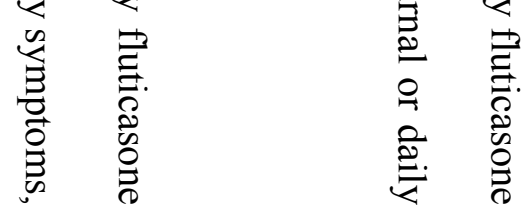

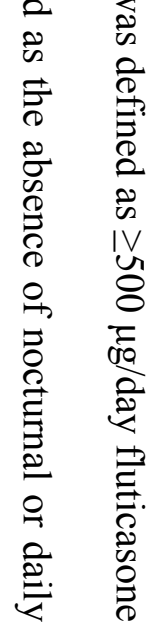




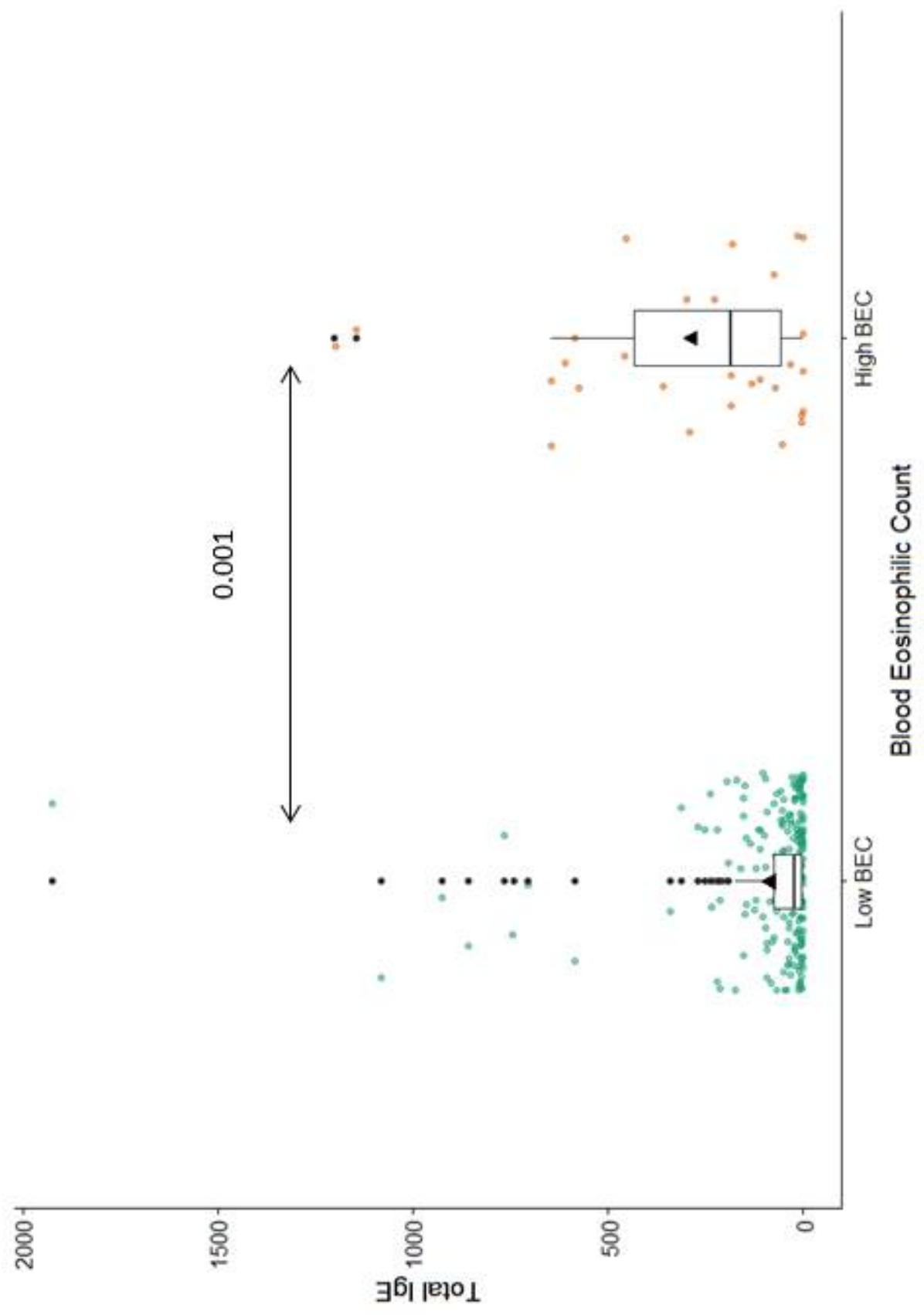



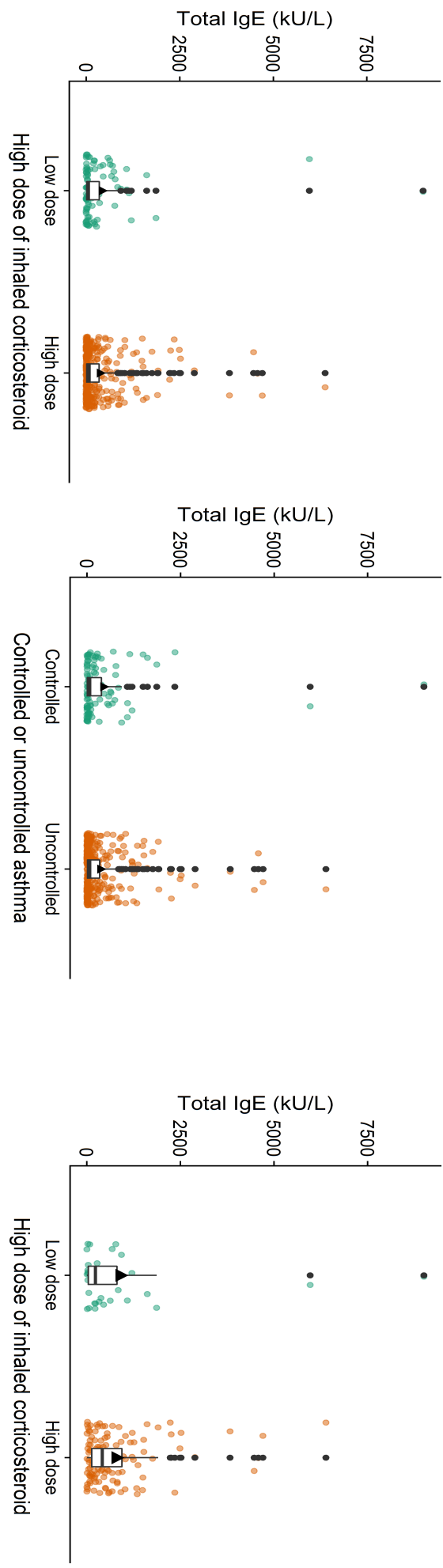

ம

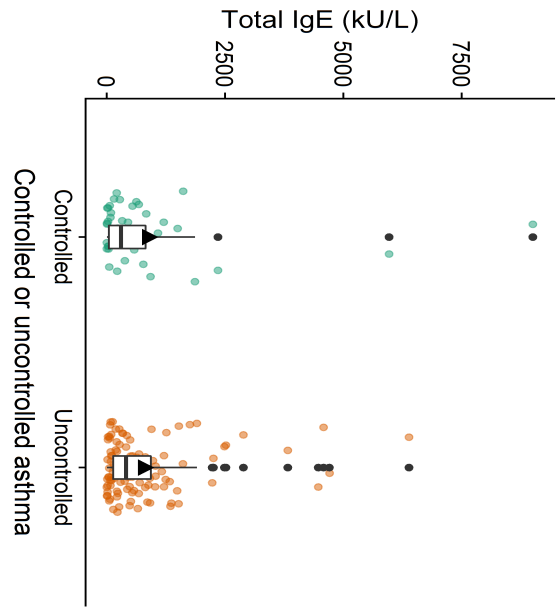




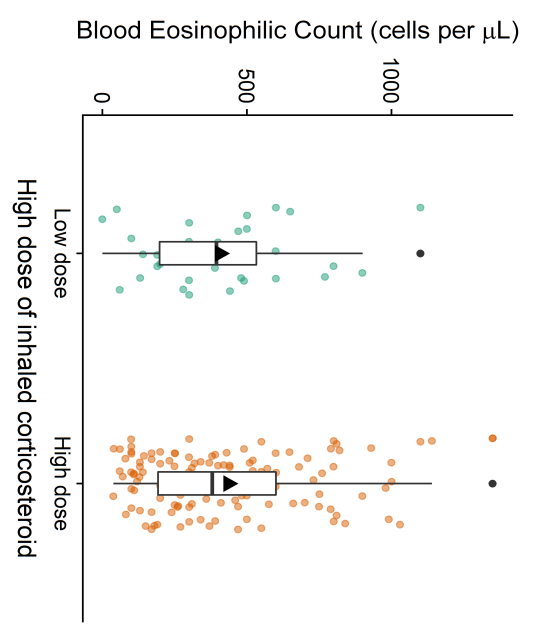

Blood Eosinophilic Count (cells per $\mu \mathrm{L}$ )
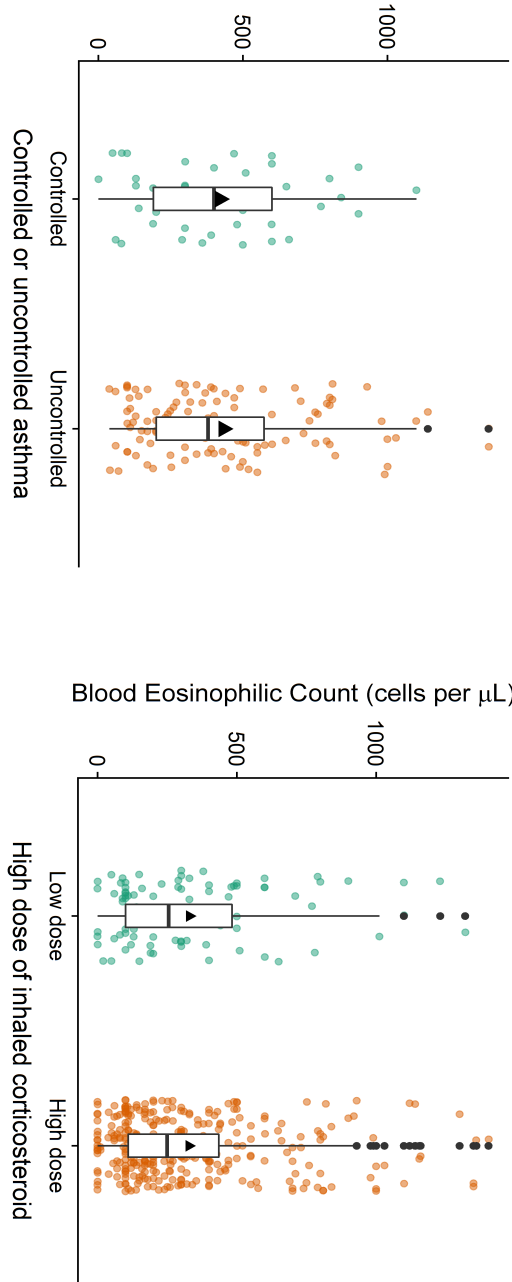

ம

Blood Eosinophilic Count (cells per $\mu \mathrm{L}$ )

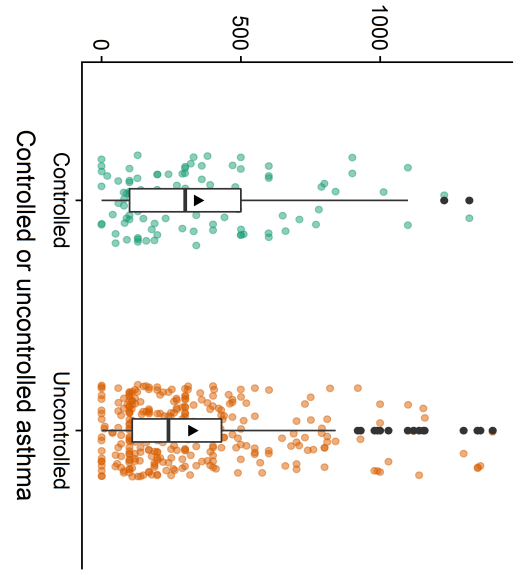

